\title{
PERCEPÇÃO DE ESTUDANTES SURDOS/AS SOBRE AS POLÍTICAS DE INCLUSÃO NA EDUCAÇÃO BÁSICA E SUPERIOR
}

\section{PERCEPCIÓN DE ESTUDIANTES SURDOS SOBRE LAS POLÍTICAS DE INCLUSIÓN EN LA EDUCACIÓN BÁSICA Y SUPERIOR}

DOI: $\underline{\text { http://dx.doi.org/10.5965/1984317815012019166 }}$

Kalline Flávia Silva de Lira

Universidade do Estado do Rio de Janeiro

kalline lira@hotmail.com

José Roniero Diodato

Universidade Federal de Pernambuco joseroniero@gmail.com

lágrici de Lima Maranhão

Faculdade Anchieta do Recife iagricimaster@gmail.com

\section{RESUMO}

Durante muito tempo as pessoas surdas não tiveram acesso a uma educação que atendesse as suas especificidades, como um currículo norteado por questões que valorizassem a cultura surda. O principal objetivo foi analisar as percepções sobre a inclusão no ensino médio e superior, a partir de uma pesquisa qualitativa, realizada através de entrevistas semiestruturadas com cinco alunos/as surdos/as da Universidade Federal de Pernambuco, egressos de uma escola regular do Recife. Os objetivos específicos foram: compreender a inclusão enquanto política pública nos documentos legislativos da educação no Brasil; verificar as possíveis discrepâncias entre o posto nos documentos normativos e a inclusão escolar de estudantes surdos/as; analisar a prática de inclusão das instituições de educação básica e superior; e identificar possíveis obstáculos que impedem e/ou impediram a materialização do processo inclusivo destes/as alunos/as surdos/as. A análise dos dados foi realizada através da técnica de análise de conteúdo. Os resultados encontrados revelaram que só a existência de leis que regulamentam a inclusão não é suficiente para a garantia da acessibilidade, pois ainda há muita dificuldade no acesso e na permanência dos/as alunos/as surdos/as no ensino básico e superior.

Palavras-chave: Políticas de inclusão. Educação do Surdo. Ensino bilíngue. Educação inclusiva.

\section{RESUMEN}

Durante mucho tiempo las personas sordas no tuvieron acceso a una educación que atendiera sus especificidades, como un currículo orientado por cuestiones que valoraran la cultura sorda. El principal objetivo fue analizar las percepciones sobre la inclusión en la enseñanza media y superior, a partir de una investigación cualitativa, realizada a través de entrevistas semiestructuradas con cinco estudiantes sordos/as de la Universidad Federal de Pernambuco, egresados de una escuela regular de Recife. Los objetivos específicos fueron: comprender la inclusión como política pública en los documentos legislativos de la educación en Brasil; verificar las posibles discrepancias entre el puesto en los documentos normativos y la inclusión escolar de estudiantes sordos; analizar la práctica de inclusión de las instituciones de educación básica y superior; e identificar posibles obstáculos que impidan y/o impidan la materialización del proceso inclusivo de estos estudiantes sordos/as. El análisis de los datos fue realizado a través de la técnica de análisis de contenido. Los resultados encontrados revelaron que sólo la existencia de leyes que regulan la inclusión no es suficiente para la garantía de la accesibilidad, pues aún hay 
mucha dificultad en el acceso y en la permanencia de los/as estudiantes sordos/as en la enseñanza básica y superior.

Palabras clave: Políticas de inclusión. Educación del Sordo. Enseñanza bilingüe. Educación inclusiva.

\section{INTRODUÇÃO}

O atual movimento pela educação inclusiva é, além de uma ação política, social e pedagógica, uma luta em defesa do direito de todo/a aluno/a em estar aprendendo e participando do processo educacional sem nenhum tipo de discriminação. Assim, a educação inclusiva é um paradigma que prima o reconhecimento do outro, o diálogo entre os diferentes grupos sociais e culturais, além do favorecimento da construção de um projeto comum, em que as diferenças sejam incluídas (CANDAU, 2008).

A Declaração Mundial sobre Educação para Todos (ONU, 1990), em seu artigo $1^{\circ}$, aponta que todas as pessoas, sejam crianças, jovens ou adultas, devem ter "condições de aproveitar as oportunidades educativas voltadas para satisfazer suas necessidades básicas de aprendizagem". Incluem-se neste ponto tanto os instrumentos para a aprendizagem, como leitura e escrita, quanto os conteúdos básicos, conhecimentos e habilidades.

A segregação escolar das pessoas com deficiência, antes vigente, precisou ser modificada, principalmente quando ficou claro que este tipo de exclusão feria todos os princípios dos direitos humanos. Foi necessária uma transformação estrutural nas escolas, que já não podiam continuar ignorando o que acontecia ao seu redor, nem tampouco continuar anulando e marginalizando as diferenças nos processos pelos quais forma e instrui os/as alunos/as (MANTOAN, 2003).

O direito à educação, visando ao pleno desenvolvimento da criança e do adolescente e o preparo para a cidadania, está posto no Estatuto da Criança e do Adolescente, no Capítulo IV, art. 53, inciso I, assegurando a "igualdade de condições para o acesso e permanência na escola" (BRASIL, 1990). Sob a ótica dos direitos deste/a estudante é que nossa discussão perpassa os caminhos que este/a aluno/a 
com deficiência, especificamente dos/as jovens surdos/as, percorreram no espaço escolar, desde o Ensino Médio até o Ensino Superior.

Esta pesquisa tem como objetivo geral analisar as percepções dos/as estudantes surdos/as sobre as políticas de inclusão do ensino médio e superior. Apontamos como objetivos específicos: compreender a inclusão enquanto política pública nos documentos legislativos da educação no Brasil; verificar as possíveis discrepâncias entre o posto nos documentos normativos e a inclusão escolar de estudantes surdos/as; analisar a prática de inclusão das instituições de educação básica e superior; e identificar possíveis obstáculos que impedem e/ou impediram a materialização do processo inclusivo destes/as alunos/as surdos/as.

Procurou-se conhecer a realidade da educação inclusiva a partir de uma pesquisa qualitativa, realizada através de entrevistas semiestruturadas com alunos/as surdas/as do curso de Letras-Libras da Universidade Federal de Pernambuco, egressos de uma escola regular, localizada na cidade do Recife - PE.

Nossa proposta é confrontar, no âmbito educacional, o Decreto n 5.626/2005 que regulamenta a Lei n 10.436/2002 que dispõe sobre a Língua Brasileira de Sinais (Libras), e a Lei n 13.146/2015, conhecida como Lei Brasileira de Inclusão (LBI), último instrumento legal relacionado às pessoas com deficiência.

Para complemento de nossa discussão e compreensão da proposta da educação para pessoas com deficiência, especificamente pessoas surdas, traremos à baila os conceitos sobre a segregação, integração e inclusão, relacionando-os ao processo histórico deste/a estudante surdo/a. Por outro lado, faremos uma ressalva ao movimento social das comunidades surdas em prol de uma educação pautada na língua de sinais através do ensino bilíngue (GOLDFELD, 2002), até a criação de políticas públicas que asseguram um ensino superior com uma abordagem adequada para educação de surdos/as, como vimos no curso de Licenciatura em Letras Libras, curso em que os sujeitos desta pesquisa estão matriculados e que é ministrado em língua de sinais. 


\section{DA SEGREGAÇÃO À INCLUSÃO}

Primeiramente, é importante entender que a deficiência é na verdade um fenômeno construído socialmente, ou seja, ser ou estar deficiente quase sempre se refere a uma comparação com as outras pessoas que são consideradas sem deficiência (AMIRALIAN, 1986). Segundo a autora, as atitudes da sociedade em relação às pessoas com deficiência mudam em função da organização social à qual estão submetidas, e, assim, na maioria das vezes são excluídas por serem grupos minoritários.

Entende-se, como aponta Skliar (2002), que a definição de grupos minoritários tem uma herança histórica, em que era imposta uma subordinação. Neste sentido, não é o quantitativo que demarca a questão do minoritário, e sim um mecanismo de poder - o poder social que cada grupo adquiriu. Como resultado, o grupo que detém o poder se impõe como superior e simboliza culturalmente o outro como inferior.

É possível enumerar algumas "fases" percorridas pelas pessoas com deficiência ao longo dos séculos. A primeira fase foi a da execução. Nas sociedades primitivas não havia pessoas com deficiência porque eram mortas ou abandonadas $A$ segunda fase foi a do misticismo. Acreditava-se que as pessoas com deficiência eram possuídas por espíritos malignos, sendo assim um objeto de temor religioso, ou ainda considerava-se a deficiência como um castigo infligido pelos deuses. Acreditavam também que a pessoa era detentora de poderes provenientes dos demônios, e suas impurezas e pecados expressavam-se pelas "marcas" - os sinais corporais que cristalizavam a evidência de maus espíritos (AMARAL, 2001).

A terceira fase, na Idade Média, foi a do enclausuramento. Como observa Fonseca (2006), o cristianismo influenciou os senhores feudais, que passaram a amparar as pessoas com deficiência e os doentes, internando-os em casas de assistência (asilos, hospitais, paróquias) que eram mantidas por eles. 
Para Amaral (2001), o fim do século XVIII e começo do XIX marcaram uma mudança e um avanço na história, surgindo instituições especializadas no atendimento a pessoas com deficiência, passando, assim, para a $4^{a}$ fase, a da exclusão. Nesse período, o Abade Charles Michel de l'Épée fundou o Instituto Nacional de Jovens Surdos de Nascença de Paris. Em 1791 a escola foi instituída por lei pelas autoridades republicanas francesas, que reconheceu aos surdos o estatuto de cidadãos e o direito de receber um ensino digno (SALERNO, 2006).

Hernest Huet, professor surdo, discípulo do Abade de l'Épée, trouxe para o Brasil os princípios da língua dos sinais francesa. Com isso, o Imperial Instituto dos Surdos-Mudos do Brasil foi fundado pela lei $n^{\circ}$ 839, de 26 de setembro de 1857. Posteriormente passou a ser chamado de Instituto Nacional de Educação de Surdos (INES). O objetivo do Instituto era a educação intelectual, moral e religiosa para aquele/a que se considerava em condições de recebê-la (PINTO, 2006).

No início do século XX, a escola segregada havia-se expandido e consolidado como modelo de atendimento à pessoa com deficiência, mas foi somente na segunda metade deste mesmo século, que se passou a pensar na possibilidade de atendimento na escola regular, "desde que [a pessoa com deficiência] se adaptasse e não causasse nenhum transtorno ao contexto escolar" (BLANCO, 2003, p. 28).

Como complementam Glat e Oliveira (2003, p. 12), o modelo começou a ser implantado no Brasil desde o final da década de 1970, com "os alunos com necessidades educacionais especiais, geralmente oriundos do ensino especial, [...] inseridos na sala regular na medida em que demonstrem condições para acompanhar a turma".

Essa $5^{a}$ fase, a da integração, segundo Santos (1995), surgiu na Europa como decorrência histórica de três fatores: das duas Guerras Mundiais (1914-1918 e 19391945), do fortalecimento do movimento pelos direitos humanos e do avanço científico. Por causa dos mutilados de guerra, foi necessário criar programas sociais para reintegrar essas pessoas à sociedade. Além disso, as organizações dos direitos 
humanos passaram a se preocupar em garantir que essas pessoas, depois de reabilitadas, pudessem, de fato, reintegrarem-se socialmente. A partir dos anos 1960, a demanda em relação à pessoa com deficiência "se dará no sentido de integrá-los com base em seus direitos enquanto seres humanos e indivíduos nascidos em dada sociedade" (SANTOS, 1995, p. 22).

O princípio filosófico/ideológico que norteou a definição e as práticas de integração foi o da normalização, que visou oferecer às pessoas com deficiência condições de vida diária iguais às da sociedade em geral. Entendia-se, nesse momento, a integração como "um processo dinâmico de participação das pessoas num contexto relacional, legitimando a sua interação com o meio físico e social" (BRASIL, 1994a, p. 18). No final da década de 1960 e durante a década de 1970, criaram-se leis e programas de atendimento educacional que favoreceram a integração da pessoa com deficiência na escola regular e no mercado de trabalho. Conforme Santos (1995), a integração neste período baseava-se, sobretudo, no modelo médico de deficiência, que tinha como finalidade a adaptação da pessoa com deficiência às exigências ou necessidades da sociedade como um todo.

Ainda de acordo com Santos (1995, p. 24), "até os anos 80 a integração desenvolveu-se dentro de um contexto histórico em que pesaram questões como igualdade e direito de oportunidades". Durante a década de 1980, concretizou-se a integração da pessoa com deficiência. Em 1981, a Organização das Nações Unidas (ONU) instituiu o Ano e a Década da Pessoa Deficiente, abrindo espaço nos meios de comunicação para uma maior conscientização da sociedade. Acredita-se que o processo de integração, que buscava normalizar a pessoa com deficiência e atribuirIhe a responsabilidade de adequação ao meio social, não propõe, conforme constata Mantoan (1998), nenhuma mudança na estrutura social, pois cabia ao indivíduo à responsabilidade de se "adequar" ao sistema. Entretanto, as práticas integracionistas demonstraram que as pessoas com deficiência não precisavam e nem deviam ser excluídas socialmente. 
Apenas a partir da década de 1990, com a realização da Conferência Mundial de Educação para Todos e com a Declaração de Salamanca de Princípios, Política e Prática para as Necessidades Educativas Especiais, passou-se à $6^{\mathrm{a}}$ fase, a era da inclusão, em que as exigências não se referem apenas ao direito da pessoa com deficiência à integração social, mas sim, ao dever da sociedade, como um todo, de se adaptar às diferenças individuais (BRASIL, 1994b).

Segundo Sassaki (1998, p. 9), "a sociedade inclusiva começou a ser construída a partir de algumas experiências de inserção social de pessoas com deficiência, ainda na década de oitenta". Conforme o autor, a inclusão social é um processo que contribui para a construção de um novo tipo de sociedade através de transformações, sejam elas pequenas ou grandes, tanto nos ambientes físicos quanto na mentalidade das pessoas, e assim também na própria pessoa com deficiência.

A Convenção da Guatemala ocorrida em 1999, ratificada no Brasil pelo Decreto $n^{\circ}$ 3.956/2001 (BRASIL, 2001a), afirma que as pessoas com deficiência têm os mesmos direitos humanos e liberdades fundamentais que as demais pessoas, definindo a discriminação com base na deficiência como toda diferenciação ou exclusão que possa impedir ou anular o exercício dos direitos humanos e de suas liberdades fundamentais.

A Convenção sobre os Direitos das Pessoas com Deficiência da ONU, ratificada através do Decreto $n^{\circ}$ 6.949/2009, é o primeiro tratado internacional a vigorar com status constitucional no Brasil, e preconiza a responsabilidade e o compromisso do governo e de toda a sociedade na efetivação dos direitos das pessoas com deficiência. A Convenção também apresenta princípios importantes como o respeito pela dignidade, autonomia e liberdade, bem como a nãodiscriminação e a igualdade de oportunidades (BRASIL, 2009). No que se refere à educação, o artigo 24 pontua que deverá ser assegurado um sistema educacional inclusivo em todos os níveis, para garantir o pleno desenvolvimento das habilidades físicas e intelectuais das pessoas com deficiência. 
A legislação mais atual no Brasil sobre as garantias da pessoa com deficiência é a Lei n 13.146/2015, conhecida como Lei Brasileira de Inclusão da Pessoa com Deficiência (LBI). Após passar 15 anos tramitando no Senado, esta lei trouxe um grande avanço na definição da deficiência.

Art. $2^{\circ}$ - Considera-se pessoa com deficiência aquela que tem impedimento de longo prazo de natureza física, mental, intelectual ou sensorial, o qual, em interação com uma ou mais barreiras, pode obstruir sua participação plena e efetiva na sociedade em igualdade de condições com as demais pessoas (BRASIL, 2015).

Anteriormente chamados de deficientes, portadores de deficiência ou de necessidades especiais, a lei já registra a nomenclatura correta e mais aceita dentro do segmento: pessoa com deficiência. Posto que, estamos, antes de qualquer coisa, falando de pessoas. Com essa definição, a LBI muda a visão sobre o conceito de deficiência - que deixa de ser atribuída exclusivamente à pessoa, e passa a ser vista como consequência também da falta de acessibilidade que toda a sociedade apresenta.

Nessa perspectiva, a falta de visão, a surdez ou a condição física do cadeirante, por exemplo, são limitações funcionais, compreendidas como atributos da pessoa e inerentes à diversidade humana. Assim, a deficiência tem um caráter relacional, pois consiste na interação dos atributos pessoais com barreiras existentes no meio social, cujo resultado é a dificuldade ou o impedimento para o acesso e exercício de direitos em igualdade de condições com as demais pessoas.

Sem dúvida muitos avanços já foram alcançados, mesmo que ainda persistam algumas resistências no que se refere à transição do paradigma da integração para o da inclusão. Os motivos mais gerais para essa mudança fundamentam-se em critérios de igualdade e de caráter especificamente educacional. A inclusão escolar, especificamente, além de contribuir para o desenvolvimento da pessoa com deficiência também beneficia os/as outros/as alunos/as, pois estes/as reconhecem as 
diferenças dos/as colegas e adquirem atitudes de respeito e solidariedade em relação às pessoas com deficiência.

\section{EDUCAÇÃO ESPECIAL E EDUCAÇÃO INCLUSIVA}

A Educação Especial surgiu a partir de um modelo médico-pedagógico, de atendimento às pessoas com deficiência. Este modelo defendia o atendimento de maneira custodial e assistencialista. O modelo esteve subordinado à ação do médico não só na determinação do diagnóstico, bem como na recomendação de práticas escolares. Segundo Werneck (1997) o modelo surgiu na década de 1960 e sua principal característica é o fato de descontextualizar a deficiência sendo esta vista como um fato isolado. A origem da exclusão está nas sequelas e limitações (físicas, sensoriais, intelectuais e múltiplas) que devem ser tratadas pela medicina. Com isso, uma pessoa com grande comprometimento deverá estar em sala ou escola especial, afastada das crianças de sua faixa-etária.

No âmbito educacional surgem as salas e escolas especiais com uma proposta de atendimento segregado das demais crianças. Diante dos preconceitos que envolviam a modelo da segregação, surge outro modelo de atendimento especializado, a integração. Neste modelo, as salas eram ampliadas, mas os/as alunos/as ainda eram atendidos/as de maneira exclusiva, pois exigiam um esforço unilateral, esperava-se que a criança se adaptasse ao meio. Já na proposta de educação inclusiva este esforço é bilateral, a escola precisava se adaptar as necessidades dos/as alunos/as com deficiência e oferecer condições para que o processo de ensino aprendizagem se efetive (PRIOSTE; RAIÇA; MACHADO, 2006).

De acordo com Mazzotta (2005), na evolução da educação especial no Brasil destacam-se dois grandes períodos: o primeiro, de 1854 a 1956, marcado por 
iniciativas oficiais e particulares isoladas; e o segundo, de 1957 a 1993, caracterizado por iniciativas oficiais de âmbito nacional. O primeiro período de atendimento escolar às pessoas com deficiência foi concretizado quando D. Pedro II fundou o Imperial Instituto dos Meninos Cegos, no Rio de Janeiro, em 12 de setembro de 1854. O Decreto $n^{\circ} 408 / 1890$ mudou o nome para Instituto Nacional dos Cegos, e no ano seguinte com o Decreto $n^{0}$ 1.320/1891 mudou para Instituto Benjamim Constant (IBC), nome que continua até hoje (MAZZOTTA, 2005).

Ainda segundo Mazzotta (2005), a Lei $n^{\circ}$ 839/1857, D. Pedro II fundou o Imperial Instituto dos Surdos-Mudos, que em 1957 passou a denominar-se Instituto Nacional de Educação dos Surdos (INES). As principais características deste Instituto eram voltadas a uma educação literária e o ensino profissionalizante. Os alunos eram apenas meninos surdos, entre 7 e 14 anos. Mazzotta (2005) ressalta, entretanto, que em 1872 a população brasileira era de 15.848 cegos e 11.595 surdos, sendo que apenas 35 cegos e 17 surdos eram atendidos nessas duas instituições. Em 1874 teve início a assistência às pessoas com deficiência intelectual, no Hospital Estadual de Salvador, hoje denominado Hospital Juliano Moreira.

No começo do século $X X$, alguns trabalhos científicos e técnicos foram publicados com temas como "A educação da infância anormal da inteligência no Brasil" e "Infância retardatária", enfatizando o preconceito com que as pessoas com deficiência ainda eram vistas. Na primeira metade do século XX até 1950 havia no Brasil 40 estabelecimentos de ensino regular com atendimento escolar especial para pessoas com deficiência mental, e outros 14 que atendiam pessoas com outras deficiências. A década de 1950 acabou sendo um marco do início da emancipação das pessoas cegas quando o Conselho Nacional de Educação autorizou que estudantes cegos ingressassem nas Faculdades de Filosofia, dando a eles oportunidade profissional em nível superior (MAZZOTTA, 2005).

O segundo período (1957 a 1993) foi marcado pelo atendimento educacional aos "excepcionais", assumido a nível nacional, pelo Governo Federal, através da criação de algumas campanhas de mobilização. A partir da década de 1960, os 
serviços de reabilitação cresceram e se desenvolveram devido a um maior incentivo e apoio oferecido pelo governo (MAZZOTTA, 2005). Em 1961, com a homologação da Lei de Diretrizes e Bases da Educação Nacional (BRASIL, 1961), a educação da pessoa com deficiência passou a ser integrada ao sistema regular de ensino. A Lei apontou o direito dos "excepcionais" à educação, preferencialmente dentro do sistema geral de ensino. No entanto, essa integração não ocorreu, pois o atendimento educacional era responsabilidade de outras instituições particulares subvencionadas pelo governo.

A Lei n 5.692/1971, que alterou a Lei de Diretrizes e Bases da Educação de 1961, definiu "tratamento especial" para os alunos com "deficiências físicas, mentais, os que se encontram em atraso considerável quanto à idade regular de matrícula e os superdotados" (BRASIL, 1971). No entanto, a lei não conseguiu promover a organização de ensino capaz de atender as necessidades educacionais e terminou reforçando as classes e escolas especiais. Interessante notar que a lei não menciona as deficiências sensoriais, em que se inclui a auditiva.

A Constituição Federal do Brasil define no artigo 205 a educação como um direito de todos (BRASIL, 1988). A Lei $n^{\circ} 8.069 / 1990$, mais conhecida como Estatuto da Criança e do Adolescente (ECA), reforça os dispositivos da Constituição Federal, e afirma que toda criança e adolescente têm direito à educação, através de "igualdade de condições para o acesso e permanência na escola" (BRASIL, 1990, art. 53, inciso I). Ainda segundo o Estatuto, é dever do Estado garantir "atendimento educacional especializado aos portadores de deficiência, preferencialmente na rede regular de ensino" (BRASIL, 1990, art. 54, inciso III).

Influenciado pela Declaração Mundial de Educação para Todos (1990) e a Declaração de Salamanca (1994), o Brasil publicou em 1994 a Política Nacional de Educação Especial, que orienta o processo de "integração institucional" das pessoas com deficiência às classes comuns do ensino regular, porém daquelas que tenham condições de acompanhar as atividades no mesmo ritmo dos alunos ditos "normais" (BRASIL, 1994a). 
A Lei n 9394/1996, a conhecida Lei de Diretrizes e Bases da Educação Nacional (LDBEN), traz no seu artigo 59, inciso I, que os sistemas de ensino devem assegurar métodos e recursos que atendam às necessidades dos/as educandos/as com deficiência, transtornos globais do desenvolvimento e altas habilidades ou superdotação (BRASIL, 1996a). O Decreto $n^{0} 3.298 / 1999$ regulamentou a Lei $n^{0}$ 7.853/1989 que dispõe sobre a Política Nacional para a Integração da Pessoa Portadora de Deficiência, e definiu a educação especial como uma modalidade transversal a todos os níveis de ensino (BRASIL, 1999).

Muitos outros dispositivos, decretos, leis e convenções nacionais e internacionais fundamentam a perspectiva atual de educação inclusiva, que de forma geral garante o acesso e a permanência das pessoas com deficiência no ensino regular, atendendo as necessidades especiais dos/as alunos/as, sobretudo nas escolas públicas.

Apesar de toda essa trajetória histórica de lutas, Mazzotta (2005) ainda ressalta que a educação especial no Brasil é muito falha quanto à oferta de serviços e quanto aos recursos financeiros destinados à educação dessa população. É importante ressaltar que o processo de inclusão é muito mais do que a simples inserção dos/as alunos/as na escola, demandando uma transformação na estrutura social vigente, no sentido de se estabelecer uma sociedade que acolha aos interesses de todas as pessoas, sem qualquer tipo de discriminação.

O avanço mais recente da educação das pessoas com deficiência está posto na LBI. Segundo esta lei, as escolas privadas são proibidas de cobrarem a mais de alunos/as com deficiência, prática recorrente aqui no país. Além disso, garante a acessibilidade nas edificações e em todos os ambientes escolares, bem como a oferta de profissionais de apoio escolar. O que se espera é que essa lei não fique mais uma vez no papel, sem conseguir ser efetivada de fato. 
A perspectiva da educação inclusiva compreende que o atendimento deve envolver todos/as os/as alunos/as com deficiência, inclusive os/as estudantes surdos/as; porém ainda não considerava os aspectos linguísticos e culturais destes sujeitos de modo que garantissem um ensino bilíngue. Para Lodi e Lacerda (2009, p. 34) é importante que o estudante surdo interaja com seus pares, um "contato com interlocutores que lhe insiram em relações sociais significativas por meio da linguagem e, nesse caso, por meio de uma língua que lhe seja acessível visualmente: a língua de sinais". Para Quadros (1997), essa proposta do ensino bilíngue ministrado em língua de sinais, é mais adequado para educação destes estudantes surdos, pois considera-se a língua de sinais como língua natural.

Os estudos relacionados à educação bilíngue (LODI; LACERDA, 2009), têm apontado que a utilização das línguas de sinais nas salas bilíngues, como língua de instrução, é a forma de garantir o direito aos/às surdos/as uma educação igualitária que garanta o desenvolvimento sociocultural respeitando suas especificidades linguísticas. De acordo com os achados das pesquisas de Diodato (2016, p. 20), chegou-se a conclusão de que na educação bilíngue "o ensino não se resume apenas na circulação de duas línguas no mesmo ambiente, mas na ênfase dada a Libras como L1 (primeira língua)".

A educação é um direito de todos e dever do Estado (BRASIL, 1988), e é vital para a formação do sujeito e o desenvolvimento das sociedades. Diante disto, surgem as reivindicações dos movimentos sociais em prol da garantia desses direitos. Por longos anos fora negado, às pessoas surdas, uma educação que atendessem as suas especificidades, como um currículo norteado pelas questões que valorizassem a cultura surda (STROBEL, 2008) e consequentemente os aspectos linguísticos. Neste sentido, Quadros e Schmiedt (2006) afirmam que a língua do surdo representa papéis e valores sociais.

Consideremos, portanto, algumas concepções educacionais para o ensino da pessoa surda: o Oralismo e a Comunicação Total. Para Quadros (1997, p. 21), "o Oralismo percebe a surdez como deficiência que deve ser minimizada pela 
estimulação auditiva" e, portanto, a língua de sinais era proibida de ser utilizada dentro da sala de aula. Na Comunicação Total o ensino era baseado na oralização e, concomitantemente, nas línguas de sinais (utilizava-se a oralização e a língua de siais ao mesmo tempo), cuja proposta era desenvolver a linguagem da criança surda (QUADROS, 1997). Embora fosse permitido, o uso da língua de sinais na concepção da Comunicação Total, o ensino era baseado na língua portuguesa e, assim fragmentava a língua de sinais (GOLDFELD, 2002). Para esta autora este é o grande erro desta abordagem.

É nessa perspectiva que surge o movimento social dos surdos ${ }^{1}$, cujo objetivo era erradicar o ensino baseado no Oralismo e consequentemente na Comunicação Total, bem como lutar pelo reconhecimento da Libras e consequentemente por um ensino pautado na língua de sinais, a educação bilíngue. Como resultado dessa luta, o ano de 2002 é lembrado como um marco na história da educação dos surdos, a promulgação da Lei $n^{\circ} 10.436 / 2002$ que reconhece a Libras como língua oficial (BRASIL, 2002), regulamentada através do Decreto $n^{\circ} 5.626 / 2005$.

Ao longo dos anos este movimento ganhou mais força com o surgimento oficial do Movimento Surdo Brasileiro (CAMPELLO; REZENDE, 2014) que fortaleceu a elaboração do Plano Nacional de Educação (PNE), conforme a meta 4 estratégia 4.7 deste documento aprovado pela Lei $n^{\circ} 13.005 / 2014$ :

4.7) Garantir a oferta de educação bilíngue, em Língua Brasileira de Sinais LIBRAS como primeira língua e na modalidade escrita da Língua Portuguesa como segunda língua, aos (às) estudantes (as) surdos e com deficiência auditiva de 0 (zero) a 17 (dezessete) anos, em escolas e classes bilíngues e em escolas inclusivas, nos termos do art. 22 do Decreto no 5.626 , de 22 de dezembro de 2005, e dos arts. 24 e 30 da Convenção sobre os Direitos das Pessoas com Deficiência, bem como a adoção do Sistema Braille de leitura para cegos e surdos-cegos (BRASIL, 2014, p. 56).

\footnotetext{
${ }^{1}$ Como movimentos sociais, entendemos que seja "um grupo de pessoas, com posicionamento político e cognitivo similar, que se sentem parte de um conjunto" (SOUZA, 1999 p.38). Esse mesmo grupo de pessoas une forças com o propósito de angariar a efetivação de leis que fomentem suas necessidades, como por exemplo, a luta pela educação bilíngue feita pelo movimento surdo.
} 
Nesse contexto, a LBI surge como um novo Estatuto da Pessoa com Deficiência e fomenta nossa discussão a partir do capítulo IV parágrafo 28 , artigo IV que garante a "oferta de educação bilíngue, em Libras como primeira língua e na modalidade escrita da língua portuguesa como segunda língua, em escolas e classes bilíngues e em escolas inclusivas" (BRASIL, 2015).

Para discussão dos resultados e para confrontarmos a política de inclusão antes e depois da LBI, tomamos como base o texto da Lei estadual $n^{\circ} 14.789 / 2012$ que institui, no âmbito do estado de Pernambuco, a Política Estadual da Pessoa com Deficiência que, no entanto, não esclarece sobre o ensino da educação bilíngue para Surdos (PERNAMBUCO, 2012). A escolha da política estadual coaduna com nosso objetivo de investigar a percepção de estudantes surdos/as sobre o processo de inclusão nas escolas de ensino médio e no ensino superior.

\section{METODOLOGIA}

A pesquisa realizada tem um caráter qualitativo (TRIVIÑOS, 1987), cuja finalidade é a coleta de dados no ambiente onde acontecem os fatos. Esse tipo de pesquisa envolve a obtenção de dados descritivos, conseguidos no contato direto com a situação de enfoque, enfatizando mais o processo do que o produto (LÜDKE; ANDRÉ, 2013). Por meio da análise qualitativa foram identificadas e descritas as percepção dos/as alunos/as sobre o processo de inclusão na educação básica e no ensino superior.

Nesse sentido, optou-se por entrevistar pessoas incluídas no sistema educacional. A amostra da pesquisa foi composta por cinco alunos/as surdos/as, dos vinte e dois estudantes surdos/as matriculados/as no curso de Licenciatura em Letras Libras da Universidade Federal de Pernambuco (UFPE), com idades entre 22 e 31 anos, de diferentes gêneros e inseridos/as em turmas de períodos distintos. $O$ motivo da escolha de apenas cinco estudantes, para serem entrevistados/s, se justifica 
devido ao teor de nossa pesquisa, pois além de ser apenas uma amostra e o início de uma pesquisa mais abrangente sobre as políticas de inclusão, optamos neste artigo, problematizar as políticas de inclusão de apenas uma escola que atende a maioria dos/as estudantes do município de Recife e que hoje estão matriculados no curso superior.

A coleta dos dados ocorreu mediante a utilização de uma entrevista semiestruturada. Escolhemos a entrevista semiestruturada por acreditarmos no caráter de interação que a permeia. De acordo com Lüdke e André (2013, p.33), "o entrevistado discorre sobre o tema proposto com base nas informações que ele detém, e que no fundo, é a verdadeira razão da entrevista". As entrevistas foram realizadas em Libras, garantindo o direito da pessoa surda o uso de sua língua. As entrevistas foram realizadas por um dos pesquisadores que é intérprete de Libras, e foram filmadas para posterior transcrição e análise.

Todos/as entrevistados/as são egressos/as de uma escola estadual, que está localizada em uma área urbana no centro da capital do estado de Pernambuco. O site da Gerência de Ensino do Estado de Pernambuco informa que a escola oferece o atendimento ao surdo dividido em três segmentos: 1. Educação Infantil - classes especiais; 2. Ensino Fundamental, Médio e Educação de Jovens e Adultos (EJA) educação inclusiva; e 3. Salas de Atendimento Educacional Especializado (AEE). As salas inclusivas desenvolvem o trabalho com intérpretes, e as salas do infantil contam com professores bilíngues.

Nesta perspectiva, objetivamos compreender as articulações destes/as alunos/as dentro do sistema educacional, e como o aporte legal tem favorecido a inclusão destes sujeitos no Ensino Superior. Desta forma, a escolha pelo curso de Licenciatura em Letras Libras dá-se pelo fato de que nos últimos anos, alunos/as surdos/as passaram a fazer parte do público atendido pela instituição com cerca de 60 estudantes num total de quatro turmas. Identificamos que apenas no curso de Letras Libras, existem surdos/as usuários/as da Libras, fato que não ocorre em outros 
cursos devido a falta de Intérpretes de Libras e por não existir uma metodologia de ensino baseada na língua de sinais.

Para análise dos dados utilizou-se a técnica de análise de conteúdo, com base nas orientações de Bardin (2004). A análise do material coletado com os/as alunos/as reverbera em olhares sobre o que se pode afirmar ser a materialização do posto nos documentos oficiais normativos como a Lei Brasileira de Inclusão (BRASIL, 2015) e que potencializam as oportunidades para que as pessoas surdas tenham mais acesso ao ensino básico, e posteriormente, ao ensino superior.

\section{RESULTADOS E DISCUSSÕES}

Inicialmente, os/as alunos/as foram questionados sobre qual era 0 entendimento deles/as quando pensavam em inclusão. De forma interessante, os sujeitos relacionaram a pergunta especificamente ao seu acesso e a inclusão do grupo surdo.

\footnotetext{
E 1 - É quando existe intérprete na sala de aula.

E 3 - É quando o professor, titular da sala, sabe Libras e, portanto, consegue se comunicar com o aluno surdo.

E 4 - Quando a escola recebe os surdos e outras pessoas com deficiência.
}

Percebe-se que as falas coadunam com o Art. $3^{\circ}$ da LBI, inciso V que aponta como caminho para materialização o combate e a responsabilização do Estado por: 
expressão, à comunicação, ao acesso à informação, à compreensão, à circulação com segurança, entre outros (BRASIL, 2015).

O mesmo documento ainda apresenta nas alíneas, especificamente o item 'd', que coloca as barreiras nas comunicações e na informação, sendo que qualquer entrave, obstáculo, atitude ou comportamento que dificulte ou impossibilite a expressão ou o recebimento de mensagens e de informações por intermédio de sistemas de comunicação e de tecnologia da informação, pode inferir como uma ausência de ações do Estado para promover políticas necessárias neste sentido.

A colocação dos/as alunos/as sobre a necessidade do/a professor/a saber Libras e sua formação necessária quanto aos aspectos da inclusão também é tratada no Decreto $n^{\circ} 5.626 / 2005$. O documento em questão apresenta as diretrizes para inclusão da pessoa surda e da consolidação da Libras como disciplina curricular nos cursos para formação de professores/as. Contudo, existem lacunas no processo de formação docente, no qual a trajetória de luta, conquistas e consolidação da profissão não são solucionadas. Como exemplo, podemos citar os cursos de bacharéis que não estão dentre os contemplados pelas normativas e ainda sim, podem assumir a docência por sua formação em mestrado e doutorado.

Dessa forma, o questionamento inicial apresenta elementos que parecem distantes aos/às alunos/as à medida que, na segunda indagação - quais as atividades foram promovidas pela escola em que você se sentiu incluído/a? - os apontamentos são os mesmos da primeira pergunta.

E2 - [...] ter intérprete em sala de aula para ajudar a entender a disciplina.

E3 - Acho que quando tem acessibilidade pra todo mundo, tem intérprete.

E5 - [...] quando tem intérprete nas palestras. 
A maioria dos/as alunos/as continuou estabelecendo como elemento de inclusão a existência de intérprete. Além da interpretação em língua de sinais como uma questão de promover inclusão, os alunos surdos mencionaram que se deparam com outros estudantes com deficiência e que estes também necessitam de acessibilidade, como cegos e deficientes físicos.

Em consonância com o proposto no Decreto $n^{\circ} 5.626 / 2005$, bem como a Lei Brasileira de Inclusão (BRASIL, 2015), a ausência dos elementos que tornem o acesso e a permanência do/a aluno/a no ambiente educacional, corrobora para o entendimento de uma inclusão falaciosa e distante do objetivo apresentado na lei. Entende-se também que a materialização das diversas leis que se referem à acessibilidade, tratadas em nosso estudo, dá-se através da ação dos sujeitos, e que os sistemas compostos por pessoas necessitam da conscientização sobre a necessidade deste movimento inclusivo.

As falas dos sujeitos ainda indicam a impressão que eles/as possuem sobre a formação do/a professor/a e o trabalho do/a intérprete. A questão de ter que se utilizar dos/as intérpretes numa sala inclusiva, tendo em vista a não formação do/a professor/a titular das disciplinas para o trabalho com os/as alunos/as surdos/as, deixa uma lacuna em sua formação.

E1 - Apenas quando o professor deseja alguma informação [sobre ele, sobre o assunto da aula] solicita ao intérprete.

E4 - Tenho muito receio de entender errado o que o intérprete diz.

Neste sentido, três entrevistados/as indagam que parecem seres estranhos/as na sala de aula, devido à forma que os professores se dirigem aos surdos, ou seja, os professores destas disciplinas ministradas em língua oral, dirigindo-se aos intérpretes e não aos estudantes surdos quando querem fazer alguma pergunta ao aluno surdo. Outro estudante destaca uma não segurança no trabalho do intérprete, afirmando que 
tem receio de "entender errado". Este receio se justifica pelo fato de existirem intérpretes que não são formados na área pedagógica e que atuam no ensino médio, podendo comprometer o ato interpretativo. Ressaltamos a importância da formação em nível superior para atuação dos intérpretes, porém, isso cabe a reforma das políticas de inclusão de estudantes surdos. Outro entrevistado diz que apenas o intérprete saber Libras não garante o processo comunicativo e inclusivo. É preciso que outras pessoas da escola utilizem a língua de sinais para efetivamente favorecer a autonomia dos/as alunos/as surdos/as.

A Política Nacional de Educação Especial (BRASIL, 2008) tem por objetivo superar a exclusão escolar, mediante a matrícula de todos/as os/as alunos/as, promovendo um processo educacional igualitário tendo a reorganização das escolas como responsabilidade da educação especial para o atendimento da educação de surdos/as. Skliar (1999) afirma que o ponto central dessa educação é a diferença linguística e sociocultural entre surdos/as e ouvintes, isso justifica pela discussão da comunidade surda sobre a implantação de escolas bilíngues na promoção de uma educação pautada nas línguas de sinais. No atendimento da educação especial, os surdos são vistos apenas como pessoa com deficiência, no entanto, esta diferença linguística requer estratégias de ensino que atendam as suas especificidades.

Não diferente dessa percepção sobre como a inclusão deve ocorrer na Educação bilíngue para surdos/as, tanto a Política Nacional de Educação Especial (BRASIL, 2008) como o Decreto $n^{\circ} 5.626 / 2005$, compreendem o processo como uma ação política, cultural, social e pedagógica asseverando o direito dos/as alunos/as estarem juntos, numa mesma sala, aprendendo e interagindo, em Libras, com os professores bilíngues.

Nesse sentido, os/as entrevistados/as colocam como ações relevantes para promover esta educação inclusiva, a escola bilíngue na educação básica e a formação específica em Libras para o/a professor/a regente das escolas ou salas bilíngues. Segundo os/as alunos/as, ter garantido um ensino bilíngue como obrigatório, tendo em vista a LBI (BRASIL, 2015) e o Plano Nacional de Educação (BRASIL, 2014), 
repercutem positivamente para uma formação que lhes garantam o acesso no ensino superior, caso optem por outro curso em que as aulas são ministradas em língua oral e necessitam de Intérprete de Libras.

Os/as entrevistados/as expressam esse sentimento de não pertencimento, quando em suas falas salientam que tanto no ensino médio quanto no superior, às vezes apenas o/a intérprete é capacitado/a para o processo comunicativo em Libras. Ou seja, sendo apenas o/a intérprete um canal de comunicação entre os/as alunos/as e os demais indivíduos da escola, no caso dos que ministram as disciplinas em língua oral as impressões dos/as atendidos/as pelo sistema neste processo é ainda de sentirem-se excluídos/as, mesmo diante de normativas que amparem uma prática diferenciada para este público.

Existem alguns requisitos e critérios para o/a profissional que atua como intérprete de Libras. Diferentes órgãos e normativas apontam desde a formação até o convívio com a comunidade surda, o que estabeleceria a experiência de questões específicas (BRASIL, 1996b). Neste mesmo sentido, as Diretrizes Nacionais para Educação Especial na Educação Básica (BRASIL, 2001b), com relação ao atendimento à pessoa com surdez, aconselha que os/as professores/as intérpretes das linguagens e códigos aplicáveis, assim como nas salas de recursos que atenderá a complementação e suplementação curricular, sejam utilizados equipamentos e materiais específicos.

Mudando a perspectiva das questões aos/às alunos/as, fez-se necessário compreender que visão estes/as mesmos/as estudantes possuem da universidade, levando-se em conta que os panoramas e contextos educacionais modificaram-se com o ingresso no ensino superior.

Diante do questionamento sobre se perceberam alguma diferença entre a escola (ensino médio) e a universidade (se esta é inclusiva, se as ações para inclusão se modificam e materializam mais dentro do espaço acadêmico), os/as alunos/as pontuam aspectos semelhantes, como a ausência de profissionais capacitados em 
Libras nos diversos espaços e a consequente dificuldade no acesso à informação, aos mecanismos de ouvidoria e regulação da universidade.

Contudo, alguns/mas alunos/as também apontam aspectos positivos e que demonstram um esforço para cumprir o que está posto nos documentos normativos e nas Leis. Como exemplo, pode-se citar a colocação de um aluno que afirma perceber a universidade um diferencial, pois alguns/mas professores/as do curso de Licenciatura em Letras Libras são surdos/as, e isto aparece como um elemento relevante do processo inclusivo.

A ideia de que a inclusão surge com o intuito de quebrar paradigmas segregadores e de exclusão, provoca a necessidade de repensar os modelos e sistemas educacionais para pessoas surdas, assim como de realizar ações significativas para atender e garantir o direito de todos e todas à educação. É neste sentido que a fala do aluno quanto ao/à professor/a surdo/a no curso de Letras Libras demonstra uma evolução no rompimento com as barreiras que delimitam os recursos humanos que irão ocupar as posições de docentes.

É possível também entender essa inserção de profissionais surdos/as na esfera acadêmica como um avanço das políticas que favorecem o acesso e a permanência na Educação Básica, de forma que consequentemente, os sujeitos conseguem chegar até ao Ensino Superior, realizar concursos e ocupar as vagas que agora, mediante lei, passam a ser destinadas tanto aos surdos e pessoas com outros tipos de deficiência. Ressaltamos que ao enfatizarmos o surdo, coadunamos com o curso analisado (Letras Libras) que possui em seu quadro docente professores surdos que ministram as disciplinas em língua de sinais.

Ainda sobre os/as professores/as do curso, os/as alunos/as elencam a metodologia como o elemento que mais favorece o movimento da educação bilíngue. As falas expressam que essa metodologia diferenciada em língua de sinais está associada ao/à professor/a bilíngue (ouvinte) e ao/à professor/a surdo/a, que mediante sua formação e necessidade, percebe a importância de fomentar uma 
prática específica. A inserção de professores/as bilíngues no curso de Letras Libras deve existir, com a finalidade de atender a formação específica das pessoas surdas.

Um dado importante na fala dos/as alunos/as está na ausência de professores/as bilíngues no próprio Centro de Educação da UFPE. Uma contradição apontada pelos/as alunos/as, tendo em vista que é o local das formações para o trabalho na área pedagógica em diversas licenciaturas e áreas correlatas. Isso também é perceptível no que se refere às metodologias, quando os/as alunos/as expõem que no Centro de Artes e Comunicação (onde é ofertado o curso de Letras Libras) a metodologia de ensino é pautada em língua de sinais, mediante os/as professores/as bilíngues, enquanto que no Centro de Educação o trabalho deixa a desejar, não sendo uma prática inclusiva, já que os/as professores/as não saberem Libras, e consequentemente, ministram a aula em português com a presença do/a intérprete, utilizando-se portanto de metodologias específicas de pessoas ouvintes, tendo a necessidade de adaptação.

Questionados/as sobre que ações poderiam ser desenvolvidas para tornar a universidade mais inclusiva, os/as alunos/as asseguram que o caminho está em tornar a academia bilíngue, através da capacitação de profissionais em todas as esferas administrativas, favorecendo o acesso à comunicação dos/as estudantes surdos/as. Que os profissionais e alunos da universidade saibam Libras para estabelecer uma comunicação direta com os surdos, dessa forma, poderão se sentir incluídos na UFPE ou em qualquer instituição de ensino superior. De forma correlacionada, os/as alunos/as cobram esta ação enquanto direito previsto em lei, acessibilidade em todos os âmbitos, para a permanência destes estudantes surdos na universidade, e explanam a relevância desta ação enquanto justiça social.

\section{CONSIDERAÇÕES FINAIS}

O presente artigo revela aspectos que exigem uma reflexão sobre o processo de inclusão dos/as alunos/as surdos/as no sistema de ensino (básico e superior) no 
Estado de Pernambuco, partindo do pressuposto apresentado no Decreto $\mathrm{n}^{\circ}$ 5.626/2005 e na Política Nacional de Educação Especial na Perspectiva da Educação Inclusiva (BRASIL, 2008).

A educação no Brasil vem sofrendo mudanças significativas ao longo dos anos, buscando cada vez mais incluir no ensino regular as pessoas com deficiência, bem como pessoas surdas através de um ensino bilíngue. No entanto, essa inclusão não tem sido tarefa fácil, frente aos diversos obstáculos que perduram, como falta de preparo da comunidade escolar como um todo e a falta de acessibilidade (arquitetônica, comunicacional e atitudinal) e de recursos didáticos específicos nos espaços educacionais.

Foi possível perceber mediante o aporte teórico e nas falas dos/as alunos/as entrevistados/as neste estudo, que avanços existem, no entanto lacunas no exercício da questão bilíngue tornam a inclusão um ideal em construção. Os/as alunos/as percebem a luta e o esforço de grupos que coadunam com a conquista de leis, as quais normatizam o processo inclusivo, contudo indicam que a ausência de empenho em ações simples dificulta a inclusão.

Percebemos também, a partir das falas dos sujeitos da pesquisa, que o número de profissionais com formação em Libras é limitado e a quantidade de tradutores intérpretes de Libras com relação à demanda existentes dentro das universidades. Neste sentido, a colaboração da pesquisa é na reflexão sobre como a educação precisa caminhar na perspectiva do ensino bilíngue, inclusivo e com a presença dos profissionais em língua de sinais.

Essa pesquisa, ainda que tenha partido de um quantitativo pequeno de alunos/as, apresenta o fomento de uma discussão em torno de lutas que surgem nos movimentos sociais. A proposta de compreender a inclusão como forma de garantia dos direitos à educação e educação bilíngue com metodologias próprias das línguas de sinais, tendo em vista o poder emancipatório, também precisa ser constitutivo dos sujeitos surdos. 


\section{REFERÊNCIAS}

AMARAL, L. A. Pensar a diferença/deficiência. Brasília: CORDE, 2001.

AMIRALIAN, M. L. T. M. Psicologia do excepcional. São Paulo: EPU, 1986.

BARDIN, L. Análise de conteúdo. Lisboa: Edições 70, 2004.

BLANCO, R. Aprendendo na diversidade: Implicações educativas. Foz do Iguaçu: 2003. Disponível

em:

$<$ http://entreamigos.org.br/sites/defaut/files/textos/Aprendendo\%20na\%20Diversdade20\%20I mplica\%-C3\%A7\%C3\%B5es\%20Educativas.pdf>. Acesso em: 24 ago. 2018.

BRASIL. Lei $n^{\circ}$ 4.024, de 20 de dezembro de 1961. Lei de Diretrizes e Bases da Educação Nacional. Diário Oficial [da República Federativa do Brasil], Poder Legislativo, Brasília, DF, 27 dez. 1961, p. 11429. Disponível em: <http://www2.camara.leg.br/legin/fed/lei/19601969/lei-4024-20-dezembro-1961-353722-norma-pl.html>. Acesso em 07 abr. 2018.

BRASIL. Lei $n^{\circ}$ 5.692, de 11 de agosto de 1971. Lei de Diretrizes e Bases da Educação Nacional. Diário Oficial [da República Federativa do Brasil], Poder Legislativo, Brasília, DF, 12 ago. 1971, p. 6377. Disponível em: <http://www2.camara.leg.br/legin/fed/lei/19701979/lei-5692-11-agosto-1971-357752-norma-pl.html>. Acesso em: 07 abr. 2018.

BRASIL. Constituição da República Federativa do Brasil. Diário Oficial da União, Poder Legislativo, Brasília, DF, 05 out. 1988, Seção 1, p. 1. Disponível em: <http://www2.camara.leg.br/legin/fed/consti/1988/constituicao-1988-5-outubro-1988-322142norma-pl.html>. Acesso em: 25 abr. 2017.

BRASIL. Lei $n^{\circ} 8069$, de 13 de julho de 1990. Estatuto da criança e do adolescente. Diário Oficial da União, Poder Legislativo, Brasília, DF, 16 jul. 1990, Seção 1, p. 13563. Disponível em: $\quad<$ http://www2.camara.leg.br/legin/fed/lei/1990/lei-8069-13-julho-1990-372211-normapl.html>. Acesso em: 16 mai. 2017.

BRASIL. Política Nacional de Educação Especial. Brasília: Ministério da Educação e do Desporto Secretaria de Educação Especial, 1994a. Disponível em: $<$ https://midia.atp.usp.br/plc/plc0604/impressos/plc0604 aula04 AVA Politica 1994.pdf>. Acesso em: 05 abr. 2018.

BRASIL. Declaração de Salamanca. Sobre princípios, políticas e práticas das necessidades educativas especiais. Brasília: CORDE, 1994b. Disponível em: <http://portal.mec.gov.br/seesp/arquivos/pdf/salamanca.pdf>. Acesso em: 27 mar. 2018.

BRASIL. Lei no 9.394, de 20 de dezembro de 1996. Lei de Diretrizes e Bases da Educação Nacional. Diário Oficial da União, Poder Legislativo, Brasília, DF, 23 dez. 1996, Seção 1, p. 27833, 1996a. Disponível em: <http://www2.camara.leg.br/legin/fed/lei/1996/lei-9394-20dezembro-1996-362578-norma-pl.html>. Acesso em: 27 mar. 2018. 
BRASIL. O Surdo e Língua de Sinais. Brasília: Coordenadoria Nacional para a Integração da Pessoa Portadora de Deficiência, Câmara Técnica, 1996b.

BRASIL. Decreto $n^{\circ} 3.298$, de 20 de dezembro de 1999. Diário Oficial da União, Poder Executivo, Brasília, DF, 21 dez. 1999, Seção 1, p. 10. Disponível em: $<$ http://www2.camara.leg.br/legin/fed/decret/1999/decreto-3298-20-dezembro-1999-367725norma-pe.html>. Acesso em: 02 abr. 2018.

BRASIL. Decreto $n^{\circ} 3956$, de 8 de outubro de 2001. Promulga a Convenção Interamericana para a Eliminação de Todas as Formas de Discriminação contra as Pessoas Portadoras de Deficiência. Convenção da Guatemala. Diário Oficial da União, Poder Executivo, Brasília, DF, 9 out. 2001, Seção 1, p. 1, 2001a. Disponível em: $<$ http://www2.camara.leg.br/legin/fed/decret/2001/decreto-3956-8-outubro-2001-332660norma-pe.html>. Acesso em: 07 abr. 2018.

BRASIL. Diretrizes Nacionais para Educação Especial na Educação Básica. Brasília: Ministério da Educação, Secretaria de Educação Especial, 2001b. Disponível em: <http://unesdoc.unesco.org/images/0014/001401/140113porb.pdf>. Acesso em: 07 abr. 2018.

BRASIL. Resolução CNE/CEB no 2, de 11 de setembro de 2001. Institui Diretrizes Nacionais para a Educação Especial na Educação Básica. Brasília: Ministério da Educação, Conselho Nacional de Educação, 2001c. Disponível em: <http://portal.mec.gov.br/cne/arquivos/pdf/CEB0201.pdf>. Acesso em: 06 abr. 2018.

BRASIL. Lei $n^{\circ}$ 10.436, de 24 de Abril de 2002. Dispõe sobre a Língua Brasileira de Sinais Libras e dá outras providências. Diário Oficial da União, Poder Legislativo, Brasília, DF, 25 abr. 2002, p. 23. Disponível em: <http://www.planalto.gov.br/ccivil 03/LEIS/2002/L10436.htm>. Acesso em: 10 ago. 2017.

BRASIL. Decreto $n^{\circ} 5.626$, de 22 de dezembro de 2005. Regulamenta a Lei $n^{\circ} 10.436$, de 24 de abril de 2002, que dispõe sobre a língua brasileira de sinais - Libras, e o art. 18 da Lei $n^{\circ}$ 10.098, de 19 de dezembro de 2000. Diário Oficial da União, Poder Executivo, Brasília, DF, 23 dez. 2005, p. 28. Disponível em: <http://www.planalto.gov.br/ccivil 03/ ato20042006/2005/decreto/d5626.htm>. Acesso em: 27 de Ago. 2017.

BRASIL. Política Nacional de Educação Especial na Perspectiva da Educação Inclusiva. Brasília: Ministério da Educação, Secretaria de Educação Especial, 2008. Disponível em: $<$ http://portal.mec.gov.br/seesp/arquivos/pdf/politica.pdf>. Acesso em: 20 ago. 2017.

BRASIL. Decreto $n^{\circ} 6.949$, de 25 de agosto de 2009. Promulga a Convenção Internacional sobre os Direitos das Pessoas com Deficiência e seu Protocolo Facultativo. Diário Oficial da União, Poder Executivo, Brasília, DF, 26 ago. 2009, p. 3. Disponível em: $<$ http://www2.camara.leg.br/legin/fed/decret/2009/decreto-6949-25-agosto-2009-590871norma-pe.html>. Acesso em: 30 out. 2017. 
BRASIL. Lei no 13.005, de 25 de junho de 2014. Plano Nacional de Educação 2014-2024. Ministério da Educação. Diário Oficial da União, Poder Legislativo, Brasília, DF, 26 jun. 2014, p. 1. Disponível em: <http://www2.camara.leg.br/legin/fed/lei/2014/lei-13005-25-junho-2014778970-publicacaooriginal-144468-pl.html>. Acesso em: 30 out. 2017.

BRASIL. Lei $n^{\circ}$ 13.146, de 06 e julho de 2015. Lei Brasileira de Inclusão da Pessoa com Deficiência (Estatuto da Pessoa com Deficiência). Diário Oficial da União, Poder Legislativo, Brasília, DF, 07 jul. 2015, p. 12. Disponível em <http://www.planalto.gov.br/ccivil 03/ Ato2015-2018/2015/Lei/L13146.htm>. Acesso em: 13 ago. 2017.

CAMPELLO, A. R.; REZENDE, P. L. F. Em defesa da escola bilíngue para surdos: a história de lutas do movimento surdo brasileiro. Educar em Revista, Curitiba, Edição Especial, n. 2, p. 71-92, 2014. Disponível em: <http://www.scielo.br/pdf/er/nspe-2/06.pdf>. Acesso em: 05 abr. 2018.

CANDAU, V. M. Multiculturalismo e educação: desafios para a prática pedagógica. In: MOREIRA, A. F.; CANDAU, V. M. (Orgs). Multiculturalismo e educação: desafios para a prática pedagógica. 2. ed. Petrópolis, RJ: Vozes, 2008, p. 13-37.

DIODATO, J. R. Análise da proposta de educação para Surdos: um estudo realizado em salas bilíngues das escolas municipais do Recife. Recife, PE, 2016. Trabalho de Conclusão de Curso (Graduação em Pedagogia) - Universidade Federal de Pernambuco, UFPE, 2016.

FONSECA, R. T. M. da. O trabalho da pessoa com deficiência e a lapidação dos direitos humanos: o direito do trabalho, uma ação afirmativa. São Paulo: LTr, 2006.

GLAT, R.; OLIVEIRA, M. Políticas Educacionais e a formação de professores para a educação Inclusiva no Brasil. Revista Integração, Brasília, v. 24, p. 22-27, 2002.

GOLDFELD, M. A criança surda: linguagem e cognição numa perspectiva sociointeracionaista. São Paulo: Plexus Editora, 2002.

LODI, A. B.; LACERDA, C. B. F. de. Uma escola, duas línguas: letramento em língua portuguesa e língua de sinais nas etapas iniciais de escolarização. Porto Alegre: Mediação, 2009.

LÜDKE, M; ANDRÉ, M. E. A. Pesquisa em Educação: Abordagens Qualitativas. 2. ed. Rio de Janeiro: EPU, 2013.

MANTOAN, M. T. E. Ensino inclusivo/educação (de qualidade) para todos. Revista Integração [versão impressa], Brasília, MEC/SEESP, n. 20, 1998, p. 29-32. 
MANTOAN, M. T. E. Inclusão escolar: o que é? Por quê? Como fazer? São Paulo: Moderna, 2003.

MAZZOTTA, M. J. S. Educação especial no Brasil: história e políticas públicas. 4. ed. São Paulo: Cortez, 2005.

ONU. Organização das Nações Unidas. Declaração Mundial sobre Educação para todos. Jomtien, Tailândia: UNESCO, $1990 . \quad$ Disponível em: <http://www.dhnet.org.br/direitos/sip/onu/educar/todos.htm>. Acesso em 07 abr. 2018.

PERNAMBUCO. Lei $n^{\circ} 14.789$, de $1^{\circ}$ de outubro de 2012. Institui no âmbito do Estado de Pernambuco a Política Estadual da Pessoa com Deficiência. Diário Oficial [do Estado de Pernambuco], Poder Legislativo, Recife, PE, 02 out. 2012, p. 9. Disponível em: $<$ http://legis.alepe.pe.gov.br/texto.aspx?id=3482\&tipo=TEXTOORIGINAL>. Acesso em: 17 ago. 2017.

PINTO, F. B. O silencioso despertar do mundo surdo brasileiro. Fênix. Rev. de História e Estudos Culturais, vol. 3, n. 2, abr./jun. 2006. Disponível em: $<$ http://www.revistafenix.pro.br/PDF7/03\%20ARTIGO\%20FERNANDAPINTO.pdf>. Acesso em: 20 ago. 2018.

PRIOSTE, C.; RAIÇA, D.; MACHADO, M. L. G. Dez questões sobre a educação inclusiva da pessoa com deficiência mental. 1. ed. São Paulo: Avercamp, v. 1, 2006.

QUADROS, R. M. de. Educação de surdos: a aquisição da linguagem. Porto Alegre: Artmed, 1997.

QUADROS, R. M. de; SCHMIEDT, M. L. P. Ideias para ensinar português para alunos surdos. Brasília: MEC/SEESP, 2006.

SALERNO, M. M. Historia dos movimentos dos surdos e o reconhecimento da Libras no Brasil, Educação Temática Digital, Campinas, v.7, n.2, p.279-289, junho 2006.

SANTOS, M. P. Perspectiva histórica do movimento integracionista na Europa. Revista Brasileira de Educação Especial, Piracicaba: UNIMEP, n. 3, p. 21-29, 1995.

SASSAKI, R. Entrevista. Revista Integração [versão impressa], Brasília: MEC/SEESP, n. 20, p. 08-10, 1998.

SKLIAR, C. Atualidade da educação bilíngue para surdos. Porto Alegre: Mediação, 1999.

SKLIAR, C. Prefácio: A pergunta pelo outro da língua; a pergunta pelo mesmo da língua. In: LODI, A.; HARRISON, K.; CAMPOS, S. \& TESKE, O. (Orgs). Letramento e minorias. Porto Alegre: Editora Meditação, 2002.

STROBEL, K. As imagens do outro sobre a cultura surda. Florianópolis: Ed. da UFSC, 2008. 
TRIVIÑOS, A. N. S. Introdução à pesquisa em ciências sociais: a pesquisa qualitativa em educação. São Paulo: Atlas, 1987.

WERNECK, C. Ninguém mais vai ser bonzinho na sociedade inclusiva. Rio de Janeiro: Ed. WYA, 1997.

Recebido em 07 de Abril de 2018 Aprovado em 15 de Setembro de 2018 